\title{
Avaliação, diagnóstico e recuperação de pavimentos de concreto hidráulico em trechos localizados na Cidade de Natal/RN e na Região Metropolitana
}

\author{
Evaluation, diagnosis and recovery of hydraulic concrete flooring in stretches located in Natal/RN
}

City and in the Metropolitan Region

Evaluación, diagnóstico y recuperación de pisos de hormigón hidráulico en estrellas ubicados en la Ciudad de Natal/RN y en la Región Metropolitana

Recebido: 17/11/2021 | Revisado: 26/11/2021 | Aceito: 01/12/2021 | Publicado: 12/12/2021

Arthur Vinícius da Costa Viana
ORCID: https://orcid.org/0000-0003-3834-2295
Universidade Federal do Rio Grande do Norte, Brasil
E-mail: arthurvinicius.96@ @otmail.com
Osvaldo de Freitas Neto
ORCID: http://orcid.org/0000-0001-9488-4123
E-mail: osvaldo.neto@ufrn.br
Universidade Federal do Rio Grande do Norte, Brasil
Fagner Alexandre Nunes de França
ORCID: https://orcid.org/0000-0002-8113-622X
Universidade Federal do Rio Grande do Norte, Brasil
E-mail: fagnerfranca@ufrn.edu.br
Enio Fernandes Amorim
ORCID: https://orcid.org/0000-0001-7386-3956
E-mail: enio.amorim@ifrn.edu.br

\begin{abstract}
Resumo
A pavimentação de vias faz parte do rol de obras de infraestrutura essenciais para a dinâmica urbana. Seu desgaste é inevitável e inerente à própria utilização. O monitoramento dos diversos defeitos devido ao uso das vias é tarefa imprescindível para manutenção da sua funcionalidade e segurança. Assim, este artigo tem o objetivo de avaliar, diagnosticar e propor técnicas de recuperação e manutenção para as faixas de pavimento de concreto em dois trechos urbanos na cidade de Natal/RN e área metropolitana. Ambos os trechos avaliados foram contemplados com uma recuperação/reestruturação há aproximadamente cinco anos, mas apresentam diversas patologias nas placas de concreto do pavimento rígido. Foi aplicada a metodologia de avaliação objetiva proposta pelo Departamento Nacional de Infraestrutura de Transportes (DNIT) no Manual de Recuperação de Pavimentos Rígidos, juntamente com inspeções visuais. Os trechos puderam ser classificados como Bom, em oposição às observações de campo, quando foi possível observar a carência de reparos e manutenção em diversos pontos. A frequência de defeitos mais simples pode ser considerada elevada, mesmo com a ausência de defeitos mais graves. Isso ressalta a importância de práticas de projeto rigorosas, bem como a execução, da manutenção constante da via, práticas muitas vezes negligenciadas.
\end{abstract}

Palavras-chave: Defeitos em pavimentos; Diagnóstico de pavimentos; Pavimento rígido.

\begin{abstract}
The paving of roads plays an important role among infrastructure works essential for urban dynamics. Wear is inevitable and inherent in its use. Monitoring the various defects due to the use of roads is an essential task for maintaining its functionality and safety. In this regard, this article aims to evaluate, diagnose and propose recovery and maintenance techniques for the concrete pavement lanes in two urban avenues in the city of Natal/RN and its metropolitan area. Despite both avenues were contemplated with a recovery/restructuring approximately five years ago, they present several pathologies in the concrete slabs of the rigid pavement. The objective assessment methodology used in this study was proposed by the National Department of Transportation Infrastructure (DNIT) in the Rigid Pavement Recovery Manual, along with visual inspections. The avenues were classified as Good. On the contrary, field observations showed the lack of repairs and maintenance services at several points. The frequency of simpler defects can be considered high, even in the absence of more serious defects. This highlights the importance of rigorous design practices, as well as the construction, the constant maintenance of the road, which are frequently neglected.
\end{abstract}

Keywords: Pavements defects; Pavement diagnosis; Rigid pavements. 


\begin{abstract}
Resumen
La pavimentación de carreteras forma parte del listado de obras de infraestructura imprescindibles para la dinámica urbana. Su desgaste es inevitable e inherente a su uso. El seguimiento de los distintos defectos debidos al uso de las carreteras es una tarea fundamental para mantener su funcionalidad y seguridad. Así, este estudio tuvo como objetivo evaluar, diagnosticar y proponer técnicas de recuperación y mantenimiento de franjas de pavimento de hormigón en dos tramos urbanos de la ciudad de Natal / RN y el área metropolitana. Ambos tramos evaluados fueron contemplados con una recuperación / reestructuración hace aproximadamente cinco años, pero presentan varias patologías en las placas de hormigón del pavimento rígido. Se aplicó la metodología de evaluación objetiva propuesta por el Departamento Nacional de Infraestructura de Transporte (DNIT) en el Manual de Recuperación de Pavimentos Rígidos, junto con inspecciones visuales. Las secciones podrían clasificarse como Buenas, a diferencia de las observaciones de campo, cuando se pudo observar la falta de reparaciones y mantenimiento en varios puntos. La frecuencia de defectos más simples puede considerarse alta, incluso en ausencia de defectos más graves. Ésto subraya la importancia de las prácticas rigurosas de diseño, así como la ejecución, del mantenimiento constante de las vías, prácticas que a menudo se pasan por alto.
\end{abstract}

Palabras clave: Defectos de pavimentos; Diagnóstico de pavimentos; Pavimentos rígidos.

\title{
1. Introdução
}

Pavimentos rígidos ou pavimentos de concreto hidráulico são aqueles que possuem sua camada de rolamento constituída de concreto de cimento Portland, seja ele pré-moldado ou moldado in loco (Balbo, 2009). A primeira utilização desse tipo de pavimento foi nos Estados Unidos ainda no século XIX. Contudo, a popularização desse pavimento se deu na Alemanha durante o século XX e hoje, aproximadamente, 50\% da malha rodoviária do Japão, Alemanha, Itália, Inglaterra e Bélgica são desse tipo (Silva \& Carneiro, 2014).

No Brasil, esse tipo de pavimento é mais utilizado em pátios de terminais portuários e de aeroportos, assim como suas pistas. As rodovias em concreto não são tão comuns como nos países já citados, mas vêm tomando cada vez mais espaço especialmente em faixas que exigem alta resistência devido ao tráfego pesado. A primeira estrada brasileira revestida com concreto foi o Caminho do Mar, no estado de São Paulo, inaugurada em 1926 (Maia, 2012).

Em Natal não existiam grandes extensões de rodovias em concreto, porém, há 5 anos, alguns trechos urbanos foram reestruturados com esse tipo de pavimento para a Copa do Mundo de 2014. A Região Oeste da cidade foi a mais contemplada com esses serviços e algumas das vias reformadas foram: Av. Jerônimo Câmara, Av. Capitão Mor Gouveia e BR-226. O investimento para a realização dessas obras incluindo serviços de esgotamento sanitário e drenagem foram da ordem de $\mathrm{R} \$$ 126,5 milhões (Lima, 2016), em valores de referência de 2016.

Segundo a Confederação Nacional do Transporte (CNT), 13,9\% das rodovias do Brasil tinham seu pavimento em condições ruins ou péssimas em 2018. No Rio Grande do Norte a situação é pior, uma vez que que 19,1\% das rodovias se encontram nesse estado. Isso revela a importância da avaliação das condições dos pavimentos e das maneiras de recuperá-los.

Dentre as rodovias citadas anteriormente duas delas se destacam pelo elevado tráfego pois são corredores de acesso ao município de Macaíba (área metropolitana de Natal/RN): BR-226, denominado neste artigo por Trecho A e Avenida Capitão Mor Gouveia, definida como Trecho B. Esses trechos foram os alvos deste estudo que o qual teve como objetivo avaliar as condições atuais desses pavimentos de concreto, e propor técnicas de engenharia para recuperá-los segundo a metodologia do Manual de Recuperação de Pavimentos Rígidos (DNIT, 2010).

Segundo Manual de Recuperação de Pavimentos Rígidos do DNIT (DNIT, 2010), os defeitos em placas de concreto podem ser classificados em recuperáveis, que não demandam demolição total ou parcial da placa (e.g. fissuras, buracos e desgaste superficial) ou irrecuperáveis, que exigem a demolição e reexecução total ou parcial da placa (e.g. placa dividida, alçamento da placa e fissuras de canto).

Diversos defeitos podem ser encontrados em rodovias de concreto, descritos na norma DNIT 061/2004. Pode-se destacar as fissuras (transversais, longitudinais, de canto ou por retração plástica), os desníveis na placa (escalonamento, assentamento ou alçamento), quebras e desgaste superficial. Adicionalmente, os defeitos são classificados segundo seu grau de 
severidade em baixo, médio e alto. Os defeitos de baixa severidade causam desconforto ao rolamento. Aqueles de média severidade causam médio desconforto ao rolamento, mas sem prejuízo ao tráfego de veículos. Por fim, os defeitos de alta severidade comprometem a segurança ao rolamento e prejuízos ao tráfego de veículos, por isso, deve ser reparado imediatamente.

As correções dos defeitos encontrados em pavimentos de concreto são aplicadas segundo a necessidade de demolição total ou parcial das placas. Balbo (2009) apresenta três técnicas empregadas para isso: retrofit, resselagem de juntas e desgaste da superfície. Segundo esse autor, a técnica de retrofit consiste na execução de cortes nas placas, seguida pela introdução de barras de transferência de carga ou de ligação e o posterior preenchimento com concreto. A resselagem de juntas é um dos serviços mais comuns em pavimentos de concreto e é realizado por meio da reaplicação de material selante nas juntas. Por fim, o desgaste da superfície refere-se a uma redução na espessura da placa com o propósito de corrigir defeitos como escalonamento, irregularidades na inclinação da placa para direcionamento de água e problemas de textura (Balbo, 2009).

É inevitável que haja o surgimento de defeitos em placas de concreto utilizadas como pavimento. Por esse motivo, deve-se atentar, em projeto, para alternativas que resultem no aumento da vida útil dos pavimentos por meio da redução da velocidade de desenvolvimento de tais defeitos. Diversas iniciativas são apresentadas na literatura a esse respeito.

A inclusão de aditivos é comumente utilizada para aumento da durabilidade do pavimento de concreto. Hassan et al. (2010) estudaram a durabilidade de um pavimento de concreto com a adição de partículas ultrafinas de dióxido de titânio (TiO2). Ensaios de desgaste e de abrasão foram conduzidos para simular o tráfego de veículos em amostras de concreto adicionadas com 3\% e 5\% de TiO2 e comparadas com a amostra sem adição. Entre os principais resultados, as deformações permanentes no pavimento medidas pelas trilhas de rodas foram mínimas nas três amostras, indicando que a adição não afetou a resistência ao desgaste do concreto.

Outros aditivos podem ser empregados. Vahedifard et al. (2010) avaliaram a influência da adição de sílica ativa e de pedra-pomes na execução de um pavimento de concreto compactado a rolo (CCR) por meio de ensaios de ciclos de congelamento e descongelamento para avaliação da durabilidade. Outros ensaios foram também realizados, relacionados à trabalhabilidade e resistência à compressão. Ambos aditivos resultaram em aumento da durabilidade do concreto avaliado.

As fissuras por fadiga foram objeto de estudo de Zhi et al. (2012). Esses autores empregaram diversos aditivos (polipropileno, borracha, fibras de celulose e de Asbestos e Gilsonita), chegando a conclusão que todos induziram a maiores valores de duração dos ensaios para o início do processo de fissuramento.

Uma alternativa para incremento da resistência à tração do concreto é a adição de fibras durante sua mistura. Nobili et al. (2013) sugerem orientações para o dimensionamento de pavimentos desse tipo, baseados nos dados obtidos no monitoramento de uma seção do pavimento em obra, sujeita ao tráfego real. Para um período de quatro meses de monitoramento, foram observados níveis de deformação muito próximos daqueles encontrados antes da liberação do tráfego. Destacam, também, que o desempenho geral do pavimento parece praticamente inalterado com o tráfego no período de observação.

A junção de técnicas (adição química e de fibras) foi investigada por Salemi e Bahfarnia (2013) ao avaliarem um pavimento de concreto adicionado com fibras de polipropileno e partículas de nano sílica e nano alumina. Dentre os principais resultados, salienta-se que o concreto com adição dos três materiais apresentou o melhor desempenho nos testes realizados, mostrando-se de maior durabilidade em condições de congelamento e descongelamento.

A inclusão de materiais no concreto pode também ter o objetivo de aumentar sua vida útil. Por exemplo, a introdução de materiais geossintéticos com o objetivo de aumentar a durabilidade do pavimento é prática atual. Al-Hedad e Hadi (2019) avaliaram seis placas de concreto, três das quais reforçadas com uma geogrelha triaxial de polipropileno. Uma carga monotônica foi aplicada em pontos diferentes das placas (canto, aresta e centro), sempre num ensaio em placa não reforçada e 
em placa reforçada. A presença da geogrelha atrasou o início da formação de trincas e modificou o tipo de ruptura que ocorreu.

Salienta-se ainda que estudos sobre a durabilidade de concretos hidráulicos aplicados em pavimentos se tornam importantes em qualquer situação, inclusive quando materiais alternativos são empregados no seu traço. Sadati e Khayat (2016), por exemplo, avaliaram o desempenho de longo prazo de um pavimento de concreto hidráulico executado com agregados reciclados. Yeon (2015) avaliou o comportamento de um pavimento de concreto reforçado com uma armadura de aço contínua. Por fim, Park et al. (2008) investigou a aplicabilidade de barras poliméricas de fibra de vidro utilizadas em substituição à barras de aço no interior do pavimento e Chen et al. (2011) estudou o comportamento do pavimento após a execução de reparos. Percebe-se, diante dos numerosos estudos apresentados na literatura, que o tema da durabilidade dos concretos hidráulicos empregados em pavimentos é um campo fértil de investigação.

\section{Metodologia}

Este trabalho foi desenvolvido em dois trechos constituídos por pavimentos de concreto hidráulico, localizados na cidade de Natal/RN e área metropolitana. Os trechos estão localizados respectivamente nas rodovias BR-266 (Av. Industrial João Francisco da Mota, do km-0 ao km-2) e Av. Capitão Mor Gouveia. Esses trechos foram escolhidos para o desenvolvimento desta pesquisa, primeiramente por se tratarem de trechos urbanos com fluxo de veículos considerável, inclusive veículos pesados. Além disso, como os trechos analisados passaram por uma recuperação há aproximadamente 5 anos, pode-se verificar a partir da metodologia empregada as condições do pavimento após um intervalo de tempo relativamente curto, em se tratando de pavimentos de concreto hidráulico.

Dessa forma, os dois trechos em análise foram inspecionados e diagnosticados de acordo com os procedimentos indicados no Manual de Manutenção de Pavimentos Rígidos do DNIT, o qual tem como base os estudos de Shahim e Kohn (1979), nacionalizados nas normas DNIT 060/2004 - PRO: Pavimento rígido - Inspeção visual - Procedimento; DNIT 062/2004 - PRO: Pavimento rígido - Avaliação objetiva - Procedimento.

A inspeção visual para a obtenção de dados de campo se iniciou com a aquisição do maior número de dados possíveis da rodovia para a preparação e a divisão em trechos e amostras. Ela foi realizada na extensão integral da rodovia ou por amostragem. As placas foram minuciosamente observadas in loco com o objetivo de identificar e contabilizar os defeitos existentes. Os dados coletados foram catalogados através de fichas de campo, fotografias e anotações. A norma supracitada informa os graus de severidade para cada defeito.

Em seguida, na avaliação objetiva obteve-se a condição estrutural do pavimento a partir do cálculo do ICP. Ele foi obtido a partir dos dados gerados na inspeção visual e é utilizado para a classificação do conceito da rodovia. O ICP é definido pela equação 1:

$I C P=100-\sum_{i=j}^{p} \sum_{j=1}^{m_{i}} A\left(T_{i}, S_{j}, D_{i j}\right) F(t, q)$

Em que:

- ICP = índice de condição do pavimento, igual a 100 para um pavimento em perfeito estado;

- A = valor dedutível, dependente do tipo de defeito (Ti), grau de severidade ( $\mathrm{Sj}$ ) e densidade de defeitos (Dij), obtido através de gráficos conforme os anexos da NORMA DNIT 062/2004;

- $\mathrm{i}=$ contador para os tipos de defeitos;

- $\mathrm{j}$ = contador para os graus de severidade (alto, médio ou baixo);

- $\mathrm{p}$ = número de placas defeituosas;

- mi = número de graus de severidade para determinado defeito;

- $F(t, q)$ = função de ajustamento para defeitos múltiplos que varia com o valor dedutível somado (t) e o número de deduções $(\mathrm{q})$. 
Na prática, a metodologia consiste em obter os valores dedutíveis individualmente para cada defeito, somar esses valores para encontrar o somatório valor dedutível (CVD) para as amostras, encontrar o somatório de valores dedutíveis corrigido (VDC) e partir para o cálculo do ICP (equação 2):

$$
I C P=100-V D C
$$

Os índices de condição do pavimento (ICPs) foram obtidos para os dois trechos avaliados das rodovias de acordo com as normas citadas anteriormente. Os resultados serão apresentados a seguir e classificados de acordo com a escala do ICP mostrada na Figura 1.

Figura 1: Escala para avaliação do ICP (DNIT, 2010).

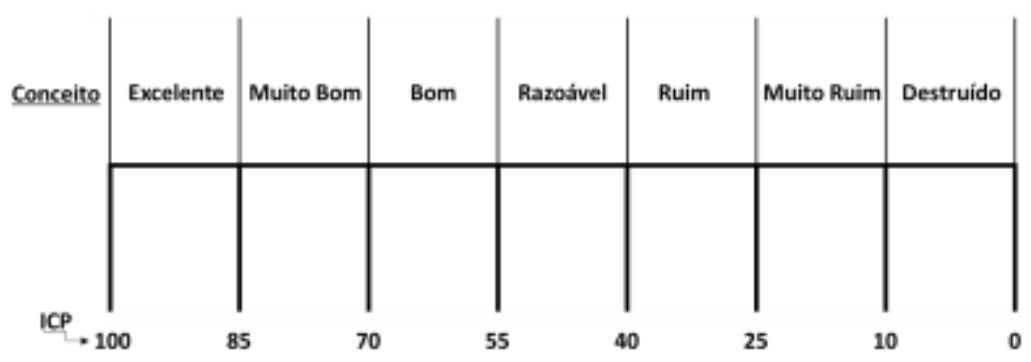

Fonte: Autores.

\subsection{Descrição dos trechos avaliados}

Os trechos rodoviários analisados nessa pesquisa correspondem ao trecho do pavimento de concreto armado da BR226 em ambos os sentidos, nas proximidades da esquina da Rua Perceval Caldas, até a Av. Capitão Mor Gouveia, ou seja, do km-0 ao km-2, aproximadamente. Com relação a Av. Capitão Mor Gouveia foi avaliada nos dois sentidos até a esquina da Rua dos Caicós, ou seja, pouco depois do Terminal Rodoviário de Natal/RN. O restante da extensão da Av. Capitão Mor Gouveia não foi avaliado por se tornar uma via de mão única. Isso reduz o fluxo de veículos sobre cada faixa e além disso há uma menor quantidade de linhas de ônibus circulando sobre a faixa exclusiva nesse trecho (apenas 7, contra 26 no trecho avaliado). Considerando os dois sentidos, a extensão avaliada nesse artigo é de aproximadamente $5,1 \mathrm{~km}$, conforme apresentado na Figura 2. A Figura 3 exemplifica a estrutura dos pavimentos utilizada para as avenidas avaliadas. A sub-base é constituída por uma brita graduada simples tratada com cimento (BGTC). O revestimento é uma camada de $25 \mathrm{~cm}$ de concreto hidráulico com resistência à tração na flexão de 4,5 MPa. 
Figura 2: Localização dos trechos rodoviários avaliados.

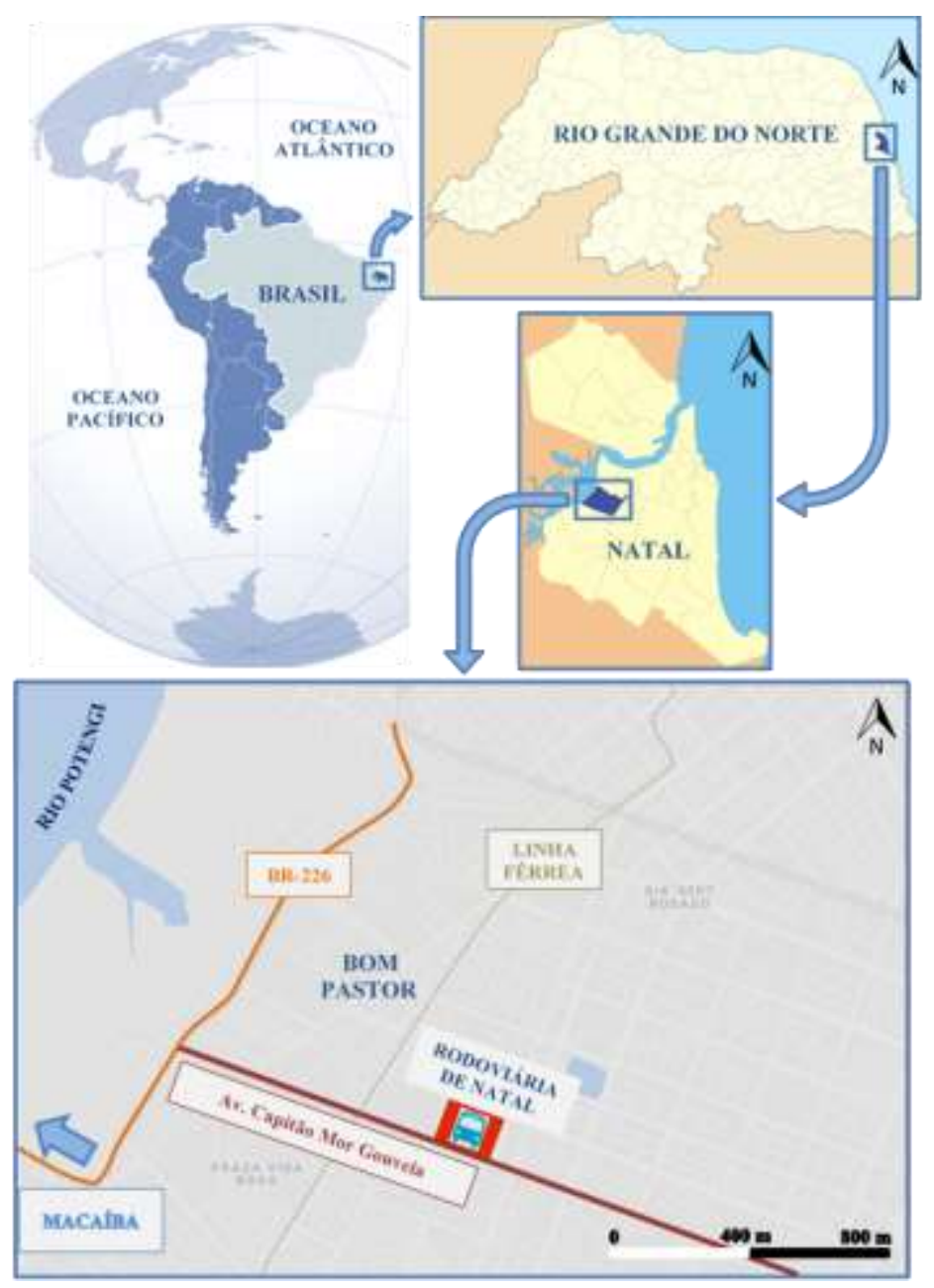

Fonte: Autores.

Figura 3: Seção transversal do pavimento de concreto no trecho da rodovia analisada (adaptado de Consórcio Ebei MWH Brasil, 2010).

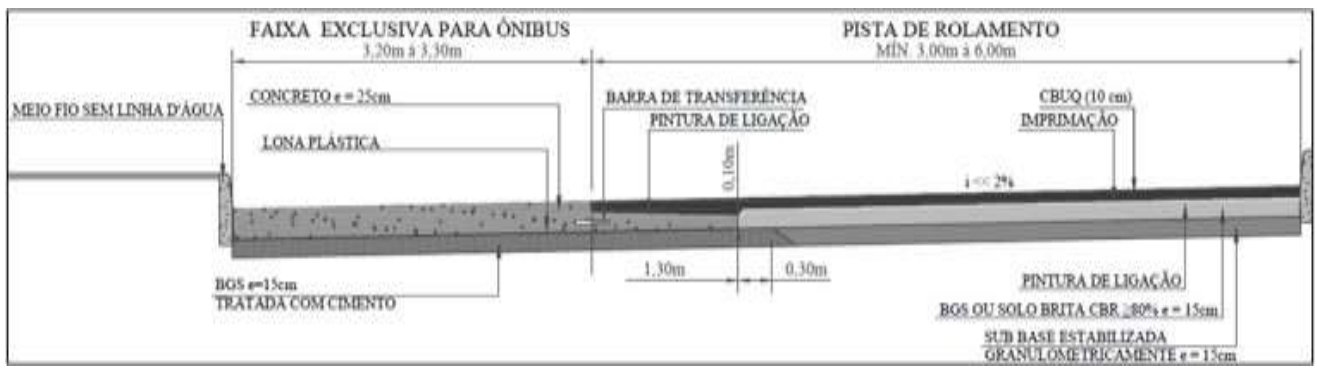

Fonte: Autores.

\section{Resultados}

\subsection{Trecho A - BR-226}

A inspeção visual revelou diversos defeitos presentes no pavimento da Av. Industrial João Francisco da Mota (BR266), km-0 ao km-2. A Figura 4 mostra exemplos das fissuras encontradas do pavimento de concreto. As causas desses defeitos vão desde problemas nas fundações do pavimento até falhas no período de cura e selagem incorreta das juntas. As 
fissuras longitudinais podem indicar recalques diferenciais causados por chuvas ou mudanças de temperatura. Esborcinamentos de juntas podem ter sido causados pelo corte de juntas prematuramente.

Figura 4: Defeitos observados nos segmentos do Trecho A: a) Fissuras transversais; b) Fissuras de canto; c) Fissuras longitudinais; d) Fissuras por retração plástica. Escalas aproximadas.
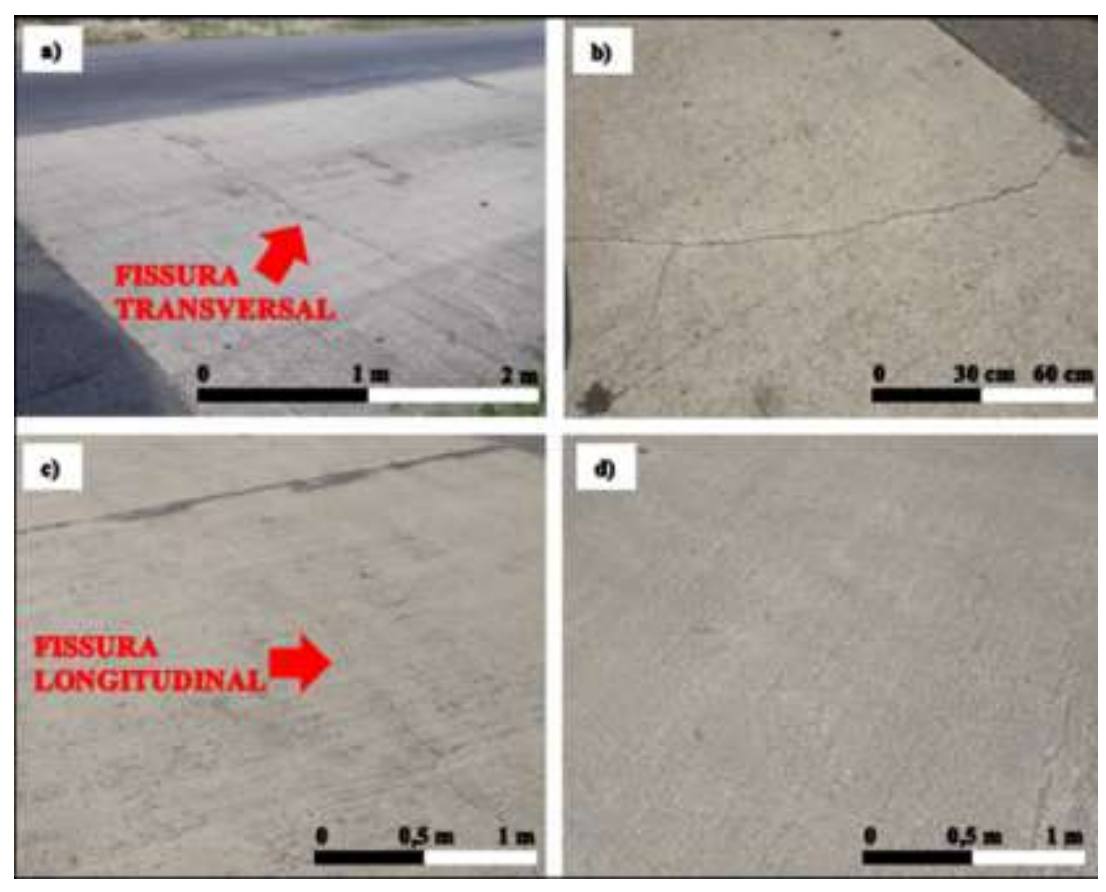

Fonte: Autores.

Outro defeito observado foram placas com desgaste superficial, com agregados a mostra evidenciando a falta de qualidade do concreto. Algumas placas também possuíam solo sobre o revestimento, onde esse material pareceu ter sido carreado das proximidades com as chuvas, alagamentos e circulação de águas servidas, uma vez que as juntas não apresentavam sinais de bombeamento. Tal premissa destaca a ineficiência ou até mesmo a inexistência de sistema de drenagem operando adequadamente.

Diversos dispositivos na rodovia, como caixas de inspeção, dispositivos de drenagem, poços de visita e outros acessórios estão causando defeitos, especialmente desníveis entre as placas (alçamento de placas ou escalonamentos), exemplificado na Figura 5. Apesar de não serem problemas intrínsecos do pavimento sua existência causa alterações no fluxo normal de veículos. 
Figura 5: Problemas encontrados nos segmentos do Trecho A: a) Comparação entre placa com desgaste superficial e placa sem esse defeito; b) Desgaste superficial, fissuras e acúmulo de solo; c) Placa dividida; d) Rendilhado e alçamento de placa devido à tampa do poço de visita. Escalas aproximadas.
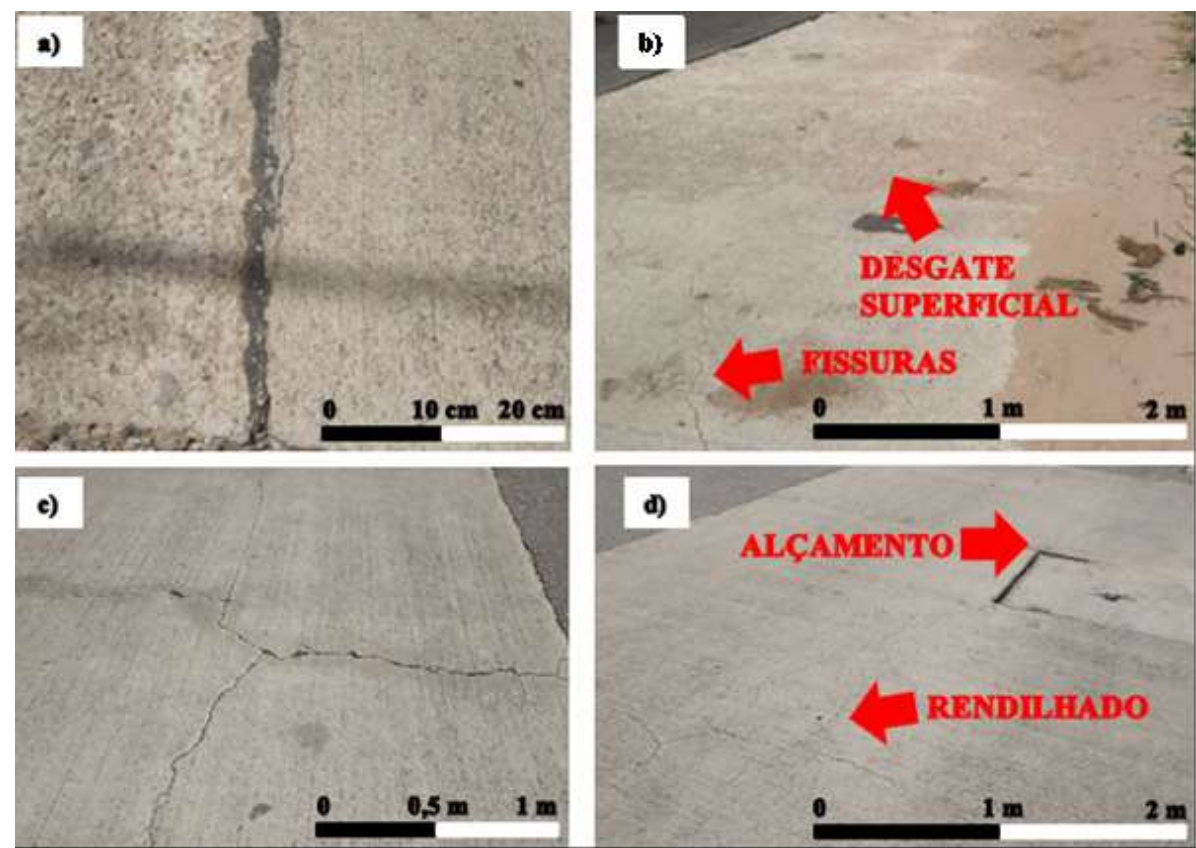

Fonte: Autores.

Nas inspeções de campo observou-se em diversos segmentos do Trecho A, significativo desnível entre o pavimento de concreto e o pavimento asfáltico em uma mesma seção transversal do pavimento. A diferença de comportamento reológico entre os dois tipos de pavimento, e o contato entre os mesmos em uma única seção transversal, sobretudo se não houver transição entre os mesmos, pode provocar desníveis abruptos, os quais podem causar acidentes e potencializar patologias no pavimento.

Como o cálculo de ICP é realizado apenas para o pavimento de concreto, os desníveis existentes nos limites das placas com o pavimento asfáltico não foram considerados. Os valores de ICP obtidos a partir dos valores dedutíveis para cada defeito e seu grau de severidade, bem como a sua relação com a condição do pavimento estão na Tabela 1.

Na Figura 6 pode-se observar a evolução de patologias em alguns segmentos da Trecho A num intervalo de tempo de um ano. Nessa Figura é possível observar o aumento da gravidade dos defeitos investigados, assim como nota-se a presença de marcas que denotam a tentativa de corrigir os problemas do pavimento. É importante ressaltar que essas correções foram realizadas após as inspeções de campo que culminaram na determinação do valor de ICP do Trecho A indicado na Tabela 1. 
Tabela 1: Defeitos encontrados e valor do ICP para a o Trecho A.

\begin{tabular}{cccccc}
\hline Item & (I) & (II) & (III) & (IV) & (V) \\
\hline $\mathbf{1}$ & Fissuras Lineares & $\mathrm{B}$ & 39 & 10,43 & 5,0 \\
$\mathbf{2}$ & Fissuras Superficiais (rendilhado) & $\mathrm{B}$ & 18 & 4,81 & 1,0 \\
$\mathbf{3}$ & Fissuração de retração plástica & - & 16 & 4,28 & 0,0 \\
$\mathbf{4}$ & Desgaste Superficial & - & 34 & 9,09 & 2,5 \\
$\mathbf{5 . a}$ & Esborcinamento de Juntas & $\mathrm{B}$ & 12 & 3,21 & 1,0 \\
$\mathbf{5 . b}$ & Esborcinamento de Juntas & $\mathrm{M}$ & 7 & 1,87 & 0,5 \\
$\mathbf{6}$ & Quebras Localizadas & $\mathrm{M}$ & 4 & 1,07 & 4,0 \\
$\mathbf{7}$ & Quebras Localizadas & $\mathrm{A}$ & 2 & 0,53 & 2,5 \\
$\mathbf{8 . a}$ & Placa Dividida & $\mathrm{M}$ & 4 & 1,07 & 4,5 \\
$\mathbf{8 . b}$ & Placa Dividida & $\mathrm{A}$ & 2 & 0,53 & 3,5 \\
$\mathbf{9}$ & Escalonamento & $\mathrm{M}$ & 6 & 1,60 & 1,5 \\
$\mathbf{1 0}$ & Alçamento de Placas & $\mathrm{A}$ & 2 & 0,53 & 3,5 \\
& Somatório do Valor Dedutível & & & & 29,5 \\
& Valor Dedutível Corrigido & & & 29,5 \\
& Índice de Condição do Pavimento (ICP) & & & 70,5 \\
\hline
\end{tabular}

Nota: (I) Defeito; (II) Grau de Severidade; (III) Quantidade de Placas Afetadas; (IV) Percentual De Placas Afetadas (\%); (V) Valor Dedutível. Fonte: Autores.

Figura 6: Correção realizada durante o ano de 2019: a) placa quebrada no início do ano; b) colapso total após chuvas; c) reparo realizado com material cimentício; d) selagem de fissuras com asfalto. Escalas aproximadas.
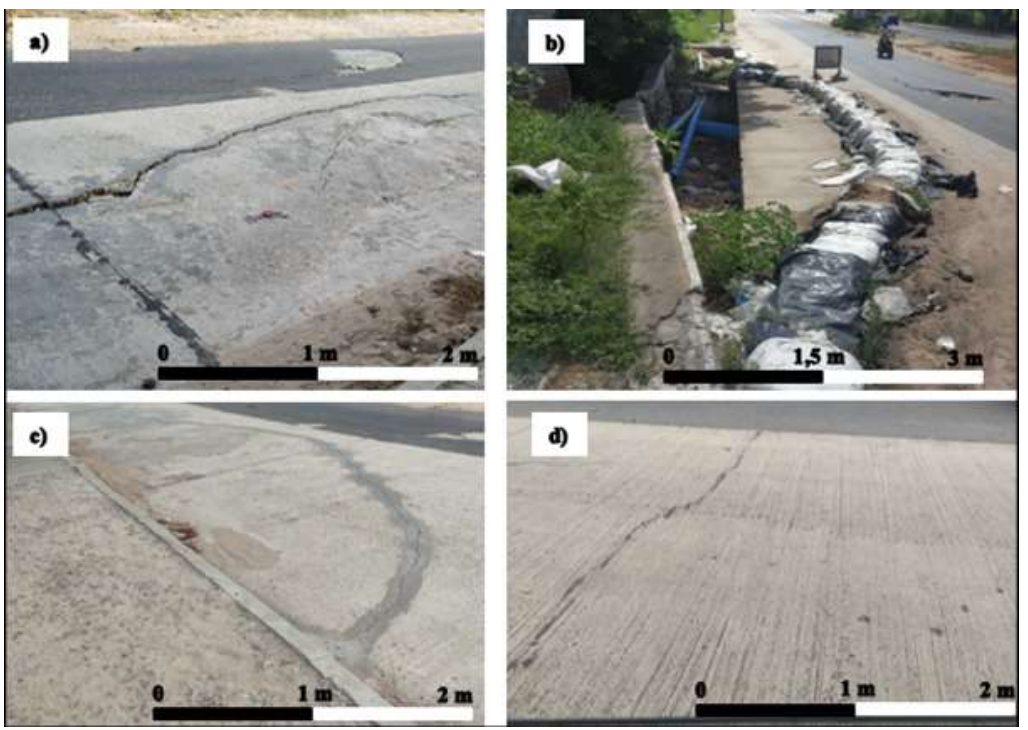

Fonte: Autores.

\subsection{Trecho B - Av. Capitão Mor Gouveia}

A inspeção no Trecho B também revelou diversos defeitos, destacando-se como os mais problemáticos ao tráfego, o escalonamento e o alçamento de placas, (Figura 7). Na Tabela 2 apresenta-se de forma sintética os defeitos encontrados durante a inspeção nesse trecho e o cálculo do ICP para o mesmo. Após a obtenção dos parâmetros ICP para o Trecho B, em nova vistoria no local, observou-se que foram realizados alguns pequenos reparos nas fissuras que podem ser observados na Figura 8. Entretanto, a maior parte dos defeitos detectados anteriormente não receberam nenhum tipo de tratamento ou reparo. 
Figura 7: Correção realizada durante o ano de 2019: a) placa quebrada no início do ano; b) colapso total após chuvas; c) reparo realizado com material cimentício; d) selagem de fissuras com asfalto. Escalas aproximadas.

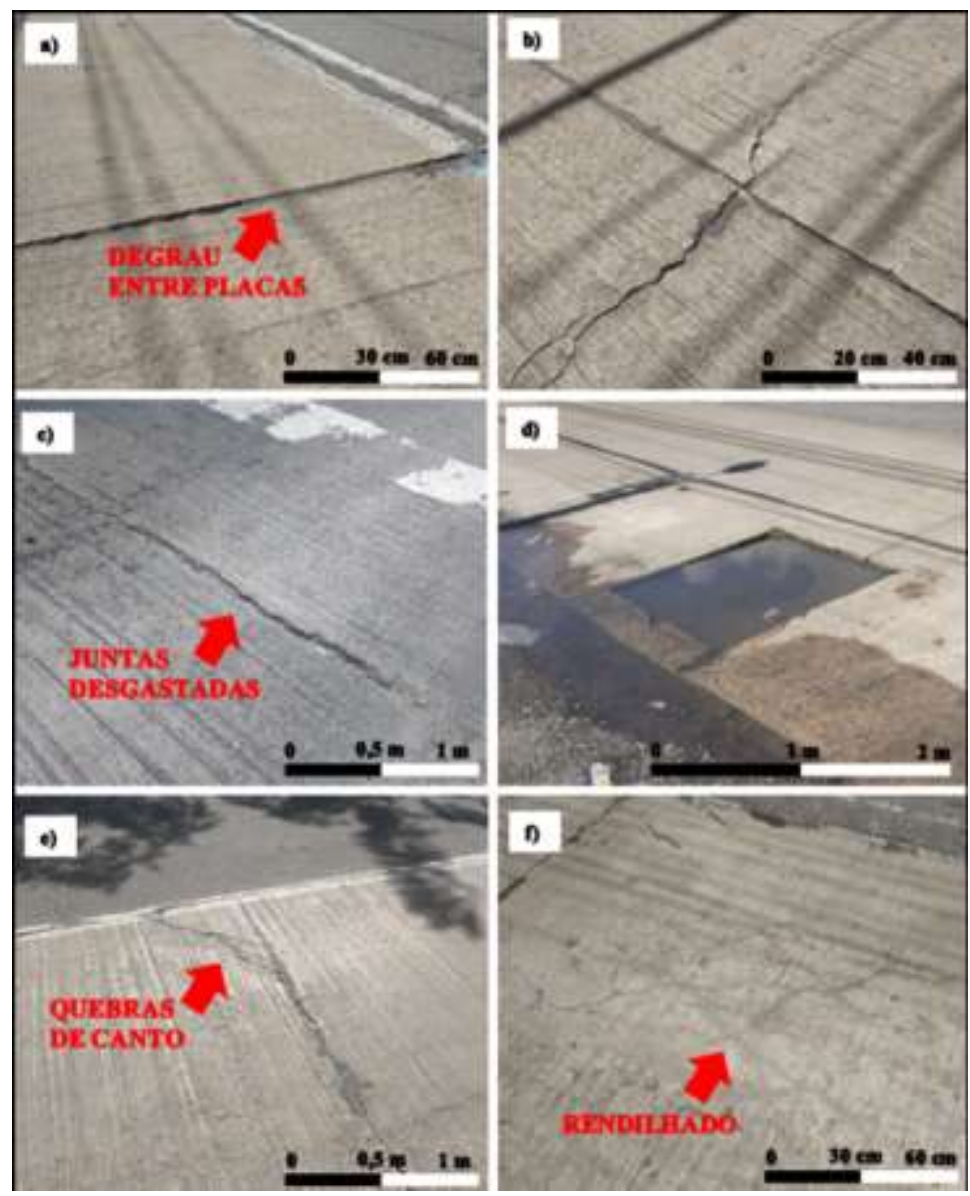

Fonte: Autores.

Tabela 2: Defeitos encontrados e valor do ICP para o Trecho B.

\begin{tabular}{clcccc}
\hline \multicolumn{1}{c}{ Item } & & (II) & (III) & (IV) & (V) \\
\hline $\mathbf{1 . a}$ & Fissuras Lineares & $\mathrm{B}$ & 27 & 5,96 & 3,5 \\
$\mathbf{1 . b}$ & Fissuras Lineares & $\mathrm{M}$ & 21 & 4,64 & 4,0 \\
$\mathbf{2}$ & Desgaste Superficial & - & 14 & 3,09 & 0,5 \\
$\mathbf{3}$ & Esborcinamento de Juntas & $\mathrm{B}$ & 8 & 1,77 & 0,5 \\
$\mathbf{4 . a}$ & Escalonamento & $\mathrm{B}$ & 7 & 1,55 & 0,0 \\
$\mathbf{4 . b}$ & Escalonamento & $\mathrm{M}$ & 15 & 3,31 & 3,0 \\
$\mathbf{5}$ & Fissuras de Retração Plástica & - & 4 & 0,88 & 0,0 \\
$\mathbf{6}$ & Quebra de Canto & $\mathrm{B}$ & 2 & 0,44 & 0,0 \\
$\mathbf{7 . a}$ & Alçamento de Placas & $\mathrm{M}$ & 4 & 0,88 & 2,0 \\
$\mathbf{7 . b}$ & Alçamento de Placas & $\mathrm{A}$ & 3 & 0,66 & 3,5 \\
$\mathbf{8}$ & Quebra de Canto & $\mathrm{M}$ & 7 & 1,55 & 0,5 \\
$\mathbf{9}$ & Quebra de Canto & M & 2 & 0,44 & 2,0 \\
$\mathbf{1 0}$ & Fissura de Canto & $\mathrm{B}$ & 2 & 0,44 & 0,5 \\
& & Somatório do Valor Dedutível & 20,0 \\
& & Valor Dedutível Corrigido & 20,0 \\
& & Índice de Condição do Pavimento (ICP) & 80,0 \\
\hline
\end{tabular}

Nota: (I) Defeito; (II) Grau de Severidade; (III) Quantidade de Placas Afetadas; (IV) Percentual De Placas Afetadas (\%); (V) Valor Dedutível. Fonte: Autores. 
Figura 8: Retrofit realizado em algumas fissuras do Trecho B.
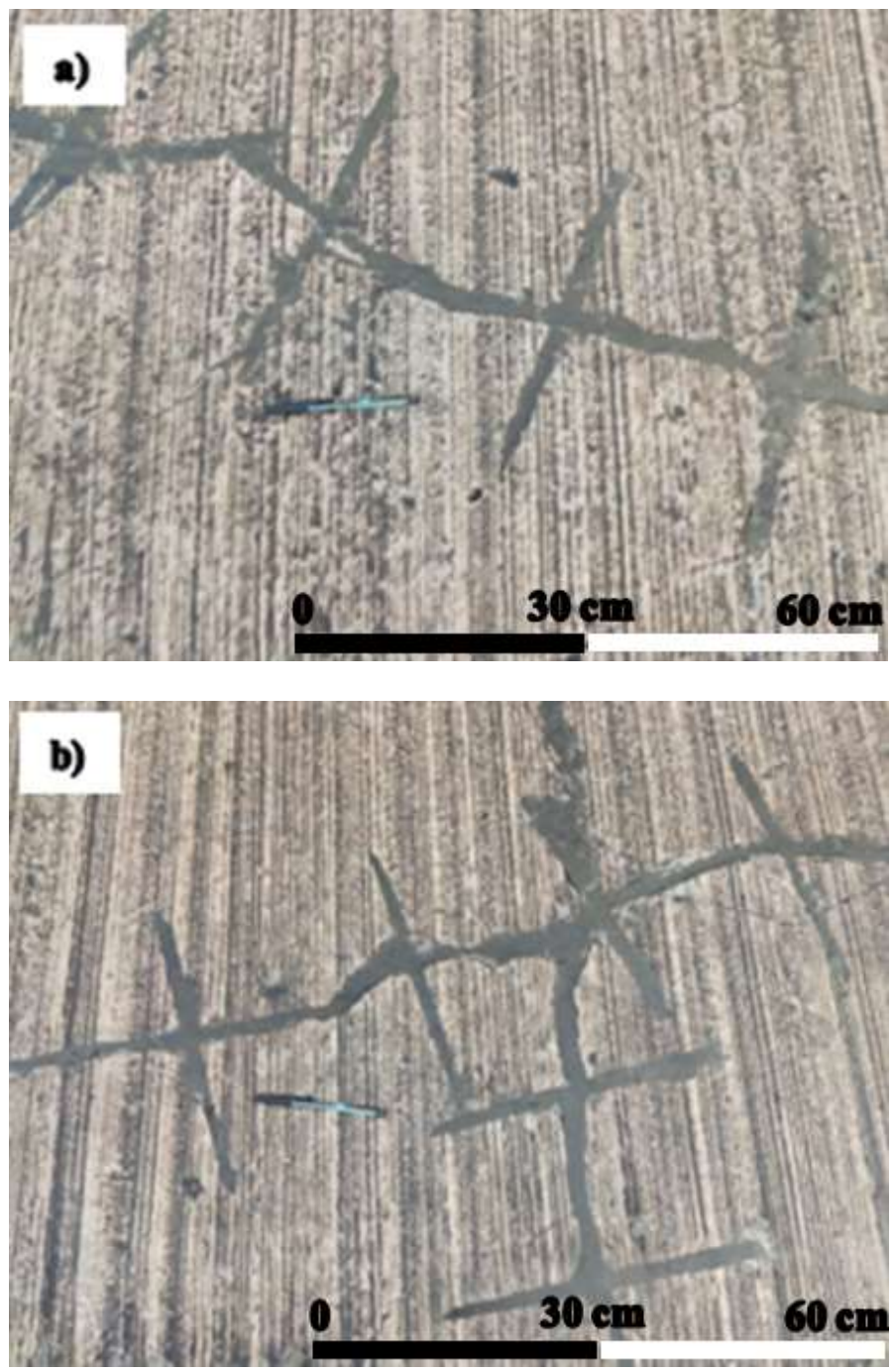

Fonte: Autores.

\section{Discussão}

Apesar de ambas as rodovias terem sidos classificadas com o conceito "Muito Bom" de acordo com a escala do DNIT, a metodologia de avaliação objetiva permite a sugestão de outro conceito pelo avaliador dadas as devidas justificativas. Em relação ao pavimento do Trecho B, o conceito é condizente com o observado durante o rolamento, ressaltando-se apenas a existência de alguns pontos de assentamento das placas. Isso causa a sensação de picos e vales, principalmente no sentido Zona Sul - Zona Oeste.

Em relação ao Trecho A, o conceito não condiz com a experiência de rolamento pois existem alguns casos observados in loco que não compõem a metodologia do DNIT: alternância abrupta entre tipos diferentes de pavimentos (concreto e asfalto) na mesma faixa de rolamento e a existência de um trecho completamente interditado. Essa interdição ocorreu devido ao carreamento do material de sub-base e subleito por vazamentos nos sistemas de drenagem e esgoto, assim como pelas chuvas, fazendo com que as placas de concreto fiquem em balanço. Além disso, o Trecho A enfrenta os mesmos problemas de assentamento que o Trecho B, principalmente no sentido Natal - Macaíba.

Além disso, há desníveis consideráveis entre a faixa de asfalto e a faixa de concreto em diversos pontos, provavelmente causados pela fluência do asfalto ou por falhas na transferência de carga entre a viga de transição e o pavimento 
de concreto. Por esses motivos, sugere-se que o conceito da faixa de concreto da BR-266 (Trecho A) deve ser considerado como "Razoável”. A Figura 9 explicita as situações supracitadas.

Figura 9: Outros problemas encontrados: a) placas em balanço; b) uma das trocas abruptas do pavimento rígido para o flexível na mesma faixa de rolamento. Escalas aproximadas.
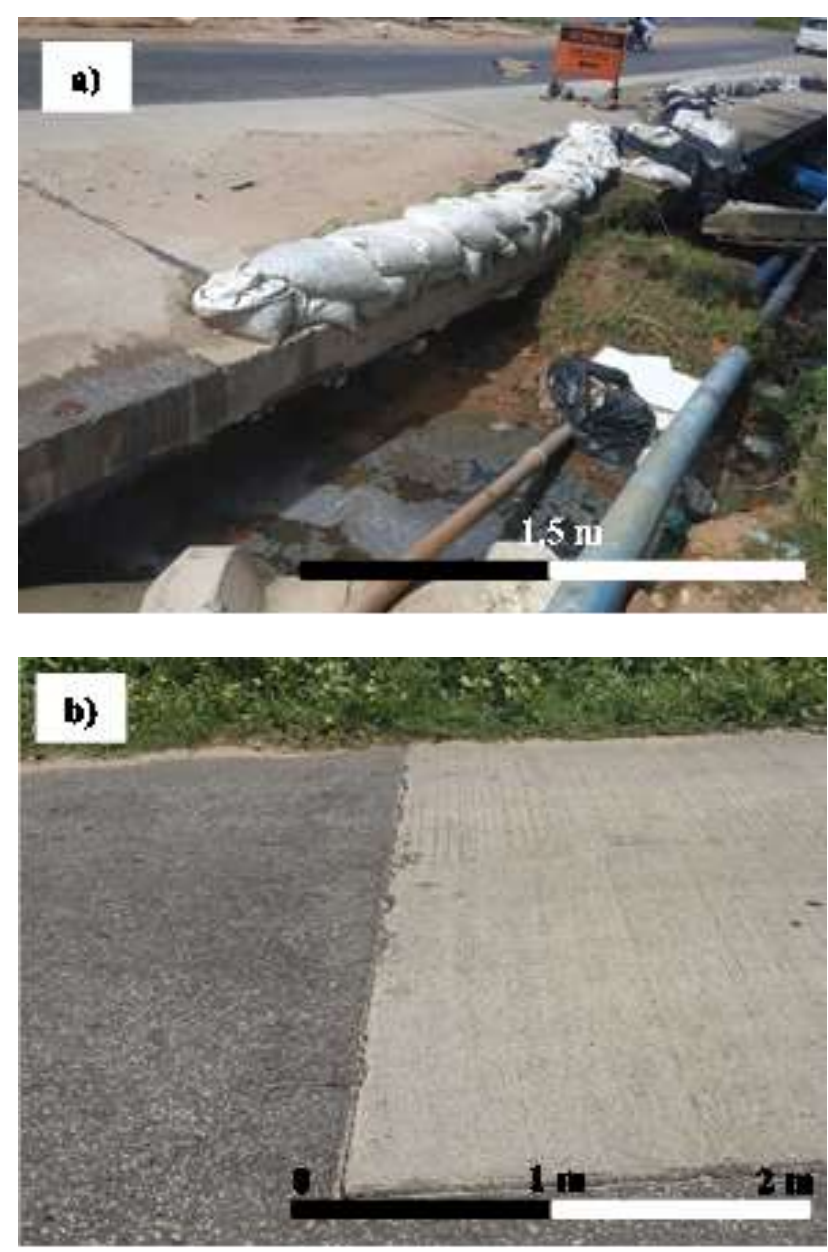

Fonte: Autores.

Para a recuperação dos defeitos encontrados recomenda-se a técnica de Retrofit para reparo das fissuras mais profundas antes que haja a quebra total da placa com ocorrência de desníveis, principalmente no Trecho B. Quanto ao Trecho A, a resselagem de juntas é necessária em diversas placas devido à ausência do material selante. As placas quebradas ou divididas como na Figura 4 (c) devem ser parcialmente refeitas nos casos mais graves e apenas seladas com asfalto nos casos mais simples.

Quanto ao defeito tipo escalonamento, pode-se afirmar que são geralmente relacionados às deficiências de transmissão de cargas entre placas. No trecho B, afirma-se que o desnível do pavimento (que está em um declive) potencializa o aparecimento desse defeito. Esses defeitos podem ser resolvidos com o desgaste superficial das placas mais elevadas, produzindo uma pequena rampa para regularizar a passagem entre elas.

As fissuras menores, de retração plástica e os desgastes superficiais podem ser reparados com selagem utilizando material asfáltico. Para obter melhores resultados nos casos de desgastes superficiais muito rasos é recomendável fresar o pavimento do concreto antes da aplicação do asfalto ou de uma nova mistura cimentícia. 
Os alçamentos de placas são advindos principalmente de acessórios do sistema de drenagem e esgotamento sanitário, portanto são problemas desses dispositivos que devem ser corrigidos, regularizando seus níveis com o nível das placas adjacentes. Os esborcinamentos de juntas podem ser minimizados com pequenos reparos com concreto e selagem com asfalto.

Em relação ao problema apresentado na Figura 8 (a), a solução indicada é a demolição parcial ou total das placas para solucionar os vazamentos nos sistemas de drenagem e/ou esgotamento sanitário e reaplicar a camada de subleito e sub-base com as características de dimensões e grau de compactação adequados já que o reparo sem a demolição das placas não foi suficiente.

\section{Conclusão}

Os pavimentos de concreto hidráulico são conhecidos por sua elevada vida útil e resistência ao tráfego pesado em relação ao pavimento asfáltico. Porém, a falta de manutenção corretiva constante faz com que a degradação desses pavimentos seja mais rápida que o esperado.

Nos casos apresentados, alguns defeitos já evoluíram para problemas mais graves pela falta de manutenção constante da via, como o esborcinamento de juntas pela falta de reposição do selante ou a divisão ou quebra de placas pela ausência de selagem das fissuras.

Isso prejudica o rolamento e o tráfego além de contribuir para maiores despesas no futuro, pois a presença de muitos defeitos, mesmo recuperáveis, fazem com que se torne mais viável a demolição completa ou parcial da placa, que no final é algo mais dispendioso que alguns reparos pontuais. Os trechos analisados não possuem problemas tão graves quanto os alçamentos de placa nos dispositivos de drenagem, porém a frequência de alguns outros defeitos mais simples é bem elevada. Isso ressalta a importância da manutenção constante da via, prática muitas vezes esquecida ou não considerada pelo poder público, já que um pavimento com uma vida útil de apenas 5 anos apresenta um conceito próximo de "Bom". Os outros problemas apresentados devem ser corrigidos o mais rápido possível para melhorar a condição do pavimento. Dessa forma, evita-se o agravamento desses defeitos, melhorando a condição de rolagem e estendendo a vida útil da rodovia.

Em relação ao pavimento asfáltico, reparos também são necessários, especialmente na região de contato com o pavimento de concreto, que possui desníveis consideráveis especialmente na Trecho A (BR-266), reduzindo o conforto do rolamento durante as trocas de faixa.

\section{Referências}

Al-Hedad, A. S. A. \& Hadi, M. N. S. (2018). Effect of geogrid reinforcement on the flexural behaviour of concrete pavements. Road Materials and Pavement Design. 20(5), 1005-25, http://dx.doi.org/10.1080/14680629. 2018.1428217.

Balbo, José Tadeu (2009). Pavimentos de Concreto. Oficina de Textos.

Chen, D.; Lin, H.; Sun, R. (2010) Field performance evaluations of partial-depth repairs. Construction and Building Materials, V.25(3), 1369-1378. http://dx.doi.org/10.1016/j.conbuildmat. 2010.09.007.

Consórcio Ebei MWH Brasil (2010). Reestruturação geométrica da Av. Capitão Mor Gouveia: Projeto de Pavimentação - detalhes das placas de concreto e das juntas de dilatação. Revisão: 003.

Departamento Nacional de Infraestrutura de Transporte - DNIT (2010). Manual de Recuperação de Pavimentos Rígidos. Instituto de Pesquisas Rodoviárias, Rio de Janeiro.

Departamento Nacional de Infraestrutura de Transporte - DNIT (2017). Glossário de Termos Técnicos Rodoviários. Instituto de Pesquisas Rodoviárias, Rio de Janeiro.

Hassan, M. M., Dylla, H., Mohammad, L. \& Rupnow, T. (2010). Evaluation of the durability of titanium dioxide photocatalyst coating for concrete pavement. Construction and Building Materials, 24(8), 1456-1461. http://dx.doi.org/10.1016/j.conbuildmat.2010.01.009.

Lima, M. (2016). Ritmo lento marca obras do KM-6. Tribuna do Norte, Natal/RN. http://www.tribunadonorte.com.br/noticia/ritmo- lento-marca-obras-do-km$6 / 340637$. 
Research, Society and Development, v. 10, n. 16, e261101623448, 2021

(CC BY 4.0) | ISSN 2525-3409 | DOI: http://dx.doi.org/10.33448/rsd-v10i16.23448

Maia, I. M. C. (2012). Caraterização De Patologias Em Pavimentos Rodoviários. 2012.97 f. Dissertação (Mestrado) - Curso de Engenharia Civil, Faculdade de Engenharia, Universidade do Porto, Porto.

Mendonça Filho, J. M. \& Rocha, E. G. A. (2018). Estudo Comparativo entre Pavimentos Flexível e Rígido na Pavimentação Rodoviária. Revista Científica Multidisciplinar Núcleo do Conhecimento. Ano 03, 6(2), 146-163.

Nobili, A., Lanzoni, L. \& Tarantino, A. M (2013). Experimental investigation and monitoring of a polypropylene-based fiber reinforced concrete road pavement. Construction and Building Materials, 47, 888-895. http://dx.doi.org/10.1016/j.conbuildmat.2013.05.077.

Park, C., Jang, C., Lee, S. W \& Won, J. P. (2008). Microstructural investigation of long-term degradation mechanisms in GFRP dowel bars for jointed concrete pavement. Journal of Applied Polymer Science, 108, 3128-3137. http://dx.doi.org/10.1002/app.27946.

Sadati, A. \& Khayat, K. (2016) Field performance of concrete pavement incorporating recycled concrete aggregate. Construction and Building Materials, 126, 691-700. http://dx.doi.org/10.1016/j.conbuildmat.2016.09.087.

Salemi, N. \& Behfarnia, K (2013). Effect of nano-particles on durability of fiber-reinforced concrete pavement. Construction and Building Materials, 48, 934941. http://dx.doi.org/10.1016/j.conbuildmat.2013.07.037.

Shahin, M. Y. \& Kohn, S. D. (1979) Technical Report - Construction and Engineering Research Laboratory: Development of a pavement condition rating procedure for roads, streets and parking lots. Department of Defense, Department of the Army, Construction Engineering Research Laboratory.

Silva, J. E. M. \& Carneiro, L. A. V. (2014). Pavimentos de Concreto: Histórico, Tipos e Modelos de Fadiga. Seção de Engenharia de Fortificação e Construção, Instituto Militar de Engenharia.

Vahedifard, F., Nili, M. \& Meehan, C. L (2010). Assessing the effects of supplementary cementitious materials on the performance of low-cement roller compacted concrete pavement. Construction and Building Materials, 24, 2528-2535. http://dx.doi.org/10.1016/j.conbuildmat.2010. 06.003.

Yeon, J. H. (2015) Implications of zero-stress temperature for the long-term behavior and performance of continuously reinforced concrete pavement. Construction and Building Materials, 91, 94-101. http://dx.doi. org/10.1016/j.conbuildmat.2015.05.043.

Zhi S., Gun, W. W., Hui, L, X \& Bo, T. (2011). Evaluation of fatigue crack behavior in asphalt concrete pavements with different polymer modifiers. Construction and Building Materials, 27, 117-125. http://dx.doi. org/10.1016/j.conbuildmat.2011.08.017. 